\title{
O IMPACTO DOS EFEITOS DA OCUPAÇÃO SOBRE A SAÚDE DE TRABALHADORES \\ II - MORTALIDADE*
}

René Mendes**

\begin{abstract}
MENDES, R. O impacto dos efeitos da ocupação sobre a saúde de trabalhadores. II - Mortalidade. Rev. Saúde públ., S. Paulo, 22:441-57, 1988.

RESUMO: Foi realizada revisão bibliográfica analítica com o objetivo de quantificar o impacto dos efeitos da ocupação sobre a mortalidade de trabalhadores em suas implicações sobre o setor saúde. As repercussões sobre a mortalidade de trabalhadores são medidas através das mortes diretamente relacionadas com o trabalho (acidentes do trabalho fatais e intoxicaçðes fatais) e das indiretamente relacionadas. Partindo das grandes causas de morte entre adultos - doenças cardiovasculares, câncer e mortes violentas - e explorando as informaçðes obtidas em estudos epidemiológicos realizados em outros países, estimou-se a força da contribuição da ocupação sobre a mortalidade. O peso e a complexidade das repercussões sobre o setor saúde pressupঠem um desempenho mais ativo na definição de políticas e responsabilidades, e na organização de açōes destinadas a identificar, reduzir ou eliminar a participação dos riscos ocupacionais nas grandes causas de doença e morte.
\end{abstract}

UNITERMOS: Mortalidade ocupacional. Riscos ocupacionais. Saúde ocupacional. Inquéritos epidemiológicos.

A "força" da influência da ocupação sobre a mortalidade de trabalhadores pode ser medida através de dois componentes, a saber:

a) componente direto, em que acidentes do trabalho ou doenças profissionais constituemse causa básica da morte. Entende-se como causa básica "a doença ou lesão que iniciou a cadeia de acontecimentos patológicos que conduziram diretamente à morte, ou as circunstâncias do acidente ou violência que produziu a lesão fatal" "’1.

b) componente indireto, tradução da influência que a ocupação ou o trabalho exercem sobre as causas "comuns" de mortalidade. Esta influência é detectada por meio de estudos epidemiológicos que mostram o predomínio de determinadas causas de morte, em diferentes ocupaçðes, ou então a precocidade da morte por causas "comuns" ou "esperadas".

\section{MORTES INDIRETAMENTE RELACIONADAS COM O TRABALHO}

Apesar da aparente maior facilidade que existe em atribuir o nexo causal entre trabalho e morte naqueles eventos típicos, 0 total de mortes diretamente causadas pelo trabalho não é fácil de ser estimado. Em países com infraestrutura de estatísticas vitais mais bem desenvolvida que no Brasil, esta dificuldade aparentemente também existe. Assim, nos Estados Unidos, por exemplo, enquanto as autoridades nacionais Occupational Safety and Health Administration (OSHA) e National Institute for Occupational Safety and Health (NIOSH) registram cerca de 13 a 14 mil óbtos diretamente causados por acidentes do trabalho, anualmente, outros estimam que pelo menos $100 \mathrm{mil}$ mortes ocorrem em cada ano, com relação direta com o trabalho ${ }^{103}$.

$\mathrm{Na}$ Grã-Bretanha, outro país onde as estatísticas vitais são exemplares, existe grande diversidade de dados. Schilling ${ }^{90}$ estima que $2 \%$ de todas as mortes de pessoas na faixa etária dos 15 aos 64 anos são diretamente causadas pelo trabalho. Isto faria com que, entre as $100 \mathrm{mil}$ mortes que anualmente ocorrem em pessoas desta faixa etária, naquele país, cerca de duas mil mortes seriam causadas pelo trabalho. Rantanen ${ }^{80}$, do Instituto de Saúde Ocupacional da

* Extraido da tese de Livre-Docência, subordinada ao título "Doutrina e prática da integração da saúde ocupacional no setor saúde: contribuição para a definição de uma política, 1986".

** Centro Latino-Americano de Segurança, Higiene e Medicina do Trabalho (CLASET), da Organizaçăo Internacional do Trabalho (OIT) - Rua Capote Valente, 710 - 05459 - Såo Paulo, SP - Brasil. 
Finlândia, estima que $1 / 3$ de todas as mortes por acidentes, naquele país, devem-se a acidentes do trabalho. Para o continente americano, tem sido estimado pela Organização PanAmericana de Saúde que ocorrem anualmente cerca de 50 mil mortes diretamente relacionadas com o trabalho ${ }^{72}$.

Para que o número de mortes diretamente atribuiveis ao trabalho possa ser conhecido no Brasil, é necessário lançar mão de diferentes fontes, a saber: estatísticas oficiais de acidentes do trabalho fatais, registrados pelo Instituto Nacional de Previdência Social (INPS), anualmente; dados sobre acidentes do trabalho na área rural, obtidos através de inquéritos; dados sobre intoxicações de origem ocupacional, fatais, a partir de centros de controle de intoxicações e de sistemas de vigilância epidemiológica de intoxicaçס̃es; dados sobre mortes violentas e, dentre estas, a proporção que é devida a acidentes do trabalho e intoxicaçסes profissionais agudas e a proporção dos acidentes de trânsito que ocorreram em situações que se caracterizam como acidente de trajeto, ou in itinere; estudos epidemiológicos que se aprofundaram no problema de acidentes de trânsito, e fontes informais que dão conta de episódios epidêmicos ocorridos com doenças profissionais de elevada letalidade. A somatória de todos esses elementos pode compor um quadro razoavelmente próximo da realidade. Seguiremos mencionan- do alguns desses indicadores, porém com a compreensão de que são fragmentos de um conjunto mais complexo, que ainda está longe de ser perfeitamente conhecido. A Tabela 1 descreve a ocorrência de acidentes do trabalho fatais, no Brasil, registrados poelo INPS, de 1970 a 1986.

A Tabela 1 pode ser analisada sob diferentes ângulos. $O$ primeiro, mais óbvio, enfoca o número absoluto de acidentes fatais ano a ano, e depois, convida a somá-los de 1970 a 1986, para chegar a uma cifra superior a 66 mil mortes. Tal dimensão, chocante demais para ser aceita, não pode passar despercebida, principalmente por se tratar de mortes evitáveis*.

Ângulo diverso para observar os mesmos números, é prestar atenção para o coeficiente de mortalidade. Se, por um lado, é justo observar a aparente tendência de declínio (de mais de 30 para menos de 20 mortes/100 mil trabalhadores), por outro, é necessário salientar que o coeficiente recentemente alcançado ainda excede em muito aqueles observados em países mais desenvolvidos. Assim, por exemplo, nos Estados Unidos, no período de 25 anos, observou-se uma redução do coeficiente, de 39 para 13 por 100 mil trabalhadores. No Estado de Maryland já se conseguiu reduzí-los a cerca de 7 por 100 mil ${ }^{6}$, coincidente, aliás, com 0 alcançado pela Finlândia ${ }^{81}$.

\section{TABELA 1}

Acidentes de trabalho fatais, no Brasil, registrados pelo INPS, de 1970 a 1986.

\begin{tabular}{lcccc}
\hline Ano & $\begin{array}{c}\text { No Trabalhadores } \\
\text { Segurados }\end{array}$ & $\begin{array}{c}\text { Acidentes } \\
\text { do } \\
\text { Trabalho }\end{array}$ & Obitos & $\begin{array}{c}\text { Mortalidade } \\
\text { por 100 mil } \\
\text { Trabalhadores }\end{array}$ \\
\hline 1970 & 7.284 .022 & 1.220 .111 & 2.232 & 30,6 \\
1971 & 7.764 .486 & 1.330 .523 & 2.587 & 33,3 \\
1972 & 8.148 .987 & 1.504 .723 & 2.805 & 34,4 \\
1973 & 10.956 .956 & 1.632 .696 & 3.122 & 28,5 \\
1974 & 11.537 .024 & 1.796 .761 & 3.764 & 32,6 \\
1975 & 12.996 .796 & 1.916 .187 & 3.942 & 30,3 \\
1976 & 14.945 .489 & 1.743 .825 & 3.900 & 26,1 \\
1977 & 16.589 .605 & 1.614 .750 & 4.445 & 23,8 \\
1978 & 18.500 .000 & 1.551 .501 & 4.342 & 22,1 \\
1979 & 20.322 .500 & 1.444 .627 & 4.800 & 20,3 \\
1980 & 23.782 .216 & 1.464 .211 & 4.808 & 19,7 \\
1981 & 24.448 .118 & 1.270 .465 & 4.496 & 21,7 \\
1982 & 20.668 .220 & 1.178 .472 & 4.214 & 18,7 \\
1983 & 22.562 .301 & 1.003 .115 & 4.508 & 18,0 \\
1984 & 25.065 .494 & 961.575 & 4.384 & -4 \\
1985 & 25.176 .791 & 1.075 .165 & 4.578 & 17,4 \\
1986 & - & 1.154 .480 & & \\
\hline
\end{tabular}

Fonte: Fundacentro - dados obtidos do INPS, não divulgados.

* Já se comparou esses números a uma guerra, para salientar a dramaticidade do problema. 
Não passou despercebida a alguns observadores e profissionais familiarizados com o problema dos acidentes de trabalho, a tendência de elevação da proporção entre o número de mortos e o total de acidentes registrados, ano a ano. Estaria esta tendência traduzindo progressivo aumento da letalidade dos acidentes (expressão da gravidade dos acidentes), ou seria um indicador do sub-registro de acidentes menos graves? Indicadores existem, e muitos, que sugerem a existência de importante sub-registro de acidentes menos graves, como aliás foi observado no estudo levado a cabo em Cubatão $0^{23,24}$.

Sobre os acidentes fatais, os dados fornecidos pelo INPS resumem-se nestes, sem que se conheçam as características pessoais dos acidentados, nem tampouco a natureza dos acidentes que mais matam, e outras informaçőes fundamentais para qualquer programa de prevenção. Contudo, alguns estudos recentemente realizados em nosso meio ajudam a esclarecer alguns desses aspectos ${ }^{26,69,95}$. Entre esses estudos, mencionamos o realizado em Campinas por Ferreira e Mendes ${ }^{26}$ que mostrou, entre outros caracteres epidemiológicos, os seguintes:

- acometimento predominante de adultos jovens $(68,3 \%$ das vítimas fatais tinham menos de 40 anos), do sexo masculino $(95,6 \%)^{*}$;

- os condutores de veículos de transporte como a categoria profissional mais acometida $(19,4 \%)$, seguida da dos serventes de obras;

- a construção civil como o ramo de atividade que mais contribui para a mortalidade por acidentes de trabalho $(29,9 \%)^{* *}$;

- os acidentes de trânsito de veículos a motor como a causa externa mais freqüente nos acidentes de trabalho fatais $(50,1 \%)$; seguem-se o grupo de "outros acidentes" $(22,9 \%)$ e o das quedas ocidentais $(12,6 \%)$;

- os traumatismos de crânio ${ }^{* * *}$ como a natureza da lesão mais freqüente nos acidentes de trabalho fatais $(54,5 \%)$; seguem-se os traumatismos de tórax, abdome e bacia $(18,5 \%)$ e as complicaçôes traumáticas e traumatismos nâo especificados e outros efeitos, de causas não especificadas $(12,9 \%)$.

Quanto às características epidemiológicas dos que morrem por acidente de trabalho, Ferreira e Mendes ${ }^{26}$ chamaram a atenção para o fator idade, afirmando que: “... é importante destacar que estão sendo vitimados por mortes prematuras e evitáveis, indivíduos extremamente jovens: mais de $2 / 3$ das vítimas fatais tinham menos de 40 anos, encontrando-se, portanto, em plena fase produtiva de sua vida. Se for considerado que a imensa maioria das vítimas é do sexo masculino $(95,6 \%)$, é possível imaginar as profundas repercussões sociais e econômicas, principalmente em nivel familiar $(62,8 \%)$ das vitimas eram casadas)".

Importante aspecto para o qual tanto o estudo realizado em Campinas - $\mathrm{SP}^{26}$ como o realizado no Estado de Maryland, EUA ${ }^{6}$ chamaram a atenção, é o da confluência de dois problemas de Saúde Pública de grande importância: o dos acidentes de trabalho e o dos acidentes de transito $^{2,47}$. Assim, em Campinas, no período de 1972 a 1978 , os acidentes de trânsito significaram cerca de $50 \%$ de todos os acidentes fatais. Evidentemente, algumas categorias profissionais - os condutores de veículos de transporte, por exemplo - ocupam proporção ainda mais elevada.

Convém lembrar que na legislação de acidentes de trabalho são previstas diferentes situações de acidentes de trânsito: se eles ocorrerem em motoristas profissinoais e seus ajudantes, são considerados acidentes de trabalho "tipo" ou "tipicos"; se ocorrrerem durante a locomoção de trabalhadores outros, indo ou voltando de seu local de trabalho, os acidenes de trânsito passam a ser configurados como "acidentes de trajeto", ou in itinere. Embora sutil, tal diferença tem evidentes implicações que devem ser consideradas no delineamento das políticas de prevenção.

Entre nós, vários estudos têm chamado a atenção para o significado crescente e a tendência epidêmica dos acidentes de trânsito. Assim, Fávero ${ }^{25}$ analisou em profundidade o problema na cidade de Ribeirão Preto - SP; Laurenti e col. ${ }^{50}$ estudaram aspectos epidemiológicos dos acidentes de trânsito na cidade de São Paulo; Pugliese e col. ${ }^{78}$ analisaram a questão na cidade de Salvador - BA; Tambellini ${ }^{95}$ estudou o problema dos acidentes de trânsito na Via Anhamgüera (no trecho entre São Paulo e Campinas);

\footnotetext{
* Teixeira ${ }^{96}$, ao analisar 206 acidentes de trabalho fatais, ocorridos em Santa Catarina, verificou que $29(14,1 \%)$ ocorreram em menores de 18 anos; $81,6 \%$ dos acidentados que morreram tinham menos de 40 anos.

** Olivan F. e col. ${ }^{70}$. observaram que na Grande São Paulo, dos acidentes de trabalho fatais, investigados a partir dos laudos do Institututo de Criminalística de São Paulo, $41,76 \%$ corresponderam a trabalhadores da construção civil.

*** Finocchiaro 27,28 , entre nós discute com propriedades o significado dos traumatismos cranianos, na infortunística do trabalho.
} 
Rodrigues ${ }^{86}$, baseando-se em dados coletados junto ao comando da Polícia Rodoviária Estadual (São Paulo) e em notícias de jornal, analisou o problema dos acidentes rodoviários com trabalhadores volantes na agricultura; e, Koizumi ${ }^{43}$, recentemente, investigou aspectos epidemiológicos dos acidentes de motocicleta no município de São Paulo.

Mello Jorge ${ }^{60,61}$, ao estudar a mortalidade por causas violentas no Município de São Paulo, no período de 1960 a 1975 , entre outros aspectos observou acentuada concentração de mortes por acidentes de trânsito na faixa etária do adulto jovem (20 a 39 anos), com uma predominância de sexo masculino em relação ao feminino, de 3:1. Entende Mello Jorge ${ }^{60}$ que "a predominância observada no sexo masculino, em todas as idades, poderia ser explicada pela maior exposição ao risco, pois os homens se locomovem mais na cidade, principalmente pela mobilidade no trabalho. Essa maior mortalidade tem sido verificada também em outras áreas". Baker ${ }^{5}$, por exemplo, ao comparar as mortes por atropelamento no Rio de Janeiro e em Baltimore, Md., observou que, diferentemente do que ocorre nos EUA, no Brasil há um predomínio de óbitos por atropelamento nas faixas etárias produtivas ( 15 a 64 anos), sugerindo que a maior exposição ao risco está associada a circunstâncias de trabalho.

Ao analisar as inter-relaçðes entre acidentes de trânsito e acidentes do trabalho, Pinto ${ }^{76}$ estimou que mais de $50 \%$ dos atropelamentos são acidentes de trabalho. Este problema é particularmente importante quando o estabelecimento de trabalho situa-se na margem de vias ou estradas de tráfego intenso. Conseqüentemente, a busca de soluções transcende as iniciativas dos órgãos diretamente envolvidos com o problema dos acidentes de trânsito, exigindo a colaboração das empresas, ainda que suas açð̃es estejam restritas ao grupamento social constituído por seus empregados e suas famílias ${ }^{57,67,79}$.

Quanto ao problema dos acidentes do trabalho fatais na área rural, infelizmente ainda existe um desconhecimento muito elevado sobre sua magnitude. Não são conhecidos dados oficiais divulgados pela Previdencia Social (PRORURAL/FUNRURAL), porém indicadores existem que permitem suspeitar de sua gravidade $52,53,54,55,92,105$. Assim, por exemplo, apenas no que se refere aos acidentes fatais devidos a agrotóxicos, os programas de vigilância epidemiológica em implantação poem à mostra o pico de um iceberg ainda não devidamente dimensionado ${ }^{94,102}$. Por exemplo, enquanto Al- meida e col. ${ }^{1}$ costumavam ser informados da ocorrência anual de 20 a 30 casos de intoxicações fatais por agrotóxicos no Estado de São Paulo, por volta de 1970, no Estado do Paraná foram notificados à Secretaria de Saúde $158 \mathrm{ca}$ sos fatais em 1984, e 106 em 1985, ocorridos dentre 2.164 intoxicaçðes agudas por pesticidas, notificadas em 1984, e 1.119 notificações em 1985*.

Dentre os escassos estudos destinados a elucidar a epidemiologia dos acidentes de trabalho fatais no meio rural, destaca-se a contribuição de Lorena ${ }^{55}$, quando em 1977 apresentou seus achados relativos ao ano agrícola $1975 / 76$, correspondentes a seis Divisðes Regionais Agrícolas (DIRAs) do Estado de São Paulo. A partir da amostragem realizada em $2 \%$ de todas as propriedades rurais da região coberta pelas seis DIRAs, o que correspondeu a 3.801 propriedades das 159.394 cadastradas na área estudada, o autor encontrou 374 propriedades em que hou. ve acidentes de trabalho no ano agrícola 75/76. Nestas, 1.463 trabalhadores se acidentaram, produzindo 26 mortes. Ao extrapolar estes dados para a área estudada, Lorena estimou em 61.300 o número de acidentados nas 6 DIRAs, ou 110.000 no Estado de São Paulo. Em relação ao número de acidentes fatais, Lorena estimou em 1.100 mortes na região, ou 2.000 mortes no Estado de São Paulo. Baseado no número de trabalhadores expostos ao risco, foi estimado que $7,3 \%$ sofreram acidentes durante um ano agrícola, e $0,13 \%$ dos trabalhadores morreram (ou $1,7 \%$ dos trabalhadores acidentados). Isto equivaleria a um coeficiente de 130 para 100.000 trabalhadores, ou seja, sete vezes o coeficiente encontrado na área urbana (que já consideramos demasiadamente elevado). Em números absolutos, o total de acidentes fatais com trabalhadores rurais no Estado de São Paulo seria quase a metade do total de aciden. tes fatais que ocorrem no setor urbano no país inteiro. Se corretas estas estimativas, estariam mostrando aspectos incomuns e dramáticos, suficientes para despertar a atenção dos vários setores envolvidos na questão, e o setor saúde não poderá ficar alheio a este problema.

\section{MORTES DIRETAMENTE RELACIONADAS COM O TRABALHO}

Se é difícil a tarefa de estimar a influência direta do trabalho sobre os aspectos qualitativos e quantitativos de mortalidade dos trabalhadores, que dizer do exercício de estimar a influên-

* Informações pessoais obtidas na Fundação de Saúde Caetano Munhoz da Rocha, Curitiba, julho de 1986. 
cia indireta? Sua detecção, como já foi antes discutido, depende de estudos epidemiológicos sobre mortalidade, os quais permitem demonstrar desigualdades na distribuição da morte quanto à idade dos que morrem e a causa de morte, quando esta distribuição leva em conta a ocupação, ou o ramo de atividade econômica, ou a classe social dos indivíduos.

Nesta seção buscaremos aprender estas diferenças, utilizando a estratégia de partir das grandes causas de morte de adultos, e explorar informações que já são conhecidas através de estudos epidemiológicos realizados em outros países, para assim chegar a estimar a "força" da contribuição da ocupação. Indiretamente se estará trabalhando com a idéia de "riscos competitivos", ou seja, o que aconteceria se não existisse a "força" da ocupação agindo na causação da morte, quer determinando a natureza (qualidade) da morte, quer tornando-a mais precoce (quantidade).

Para que este exercício inicie, será ponto de partida obrigatório saber de que morrem as pessoas, ou seja, conhecer as principais causas de mortalidade, preferentemente de adultos. Com esta finalidade são úteis os dados do estudo de Guimarães e col. ${ }^{33}$ sobre a mortalidade de adultos de 15 a 74 anos de idade em São Paulo, Botucatu e São Manoel, nos anos 1974/75, publicado em 1979.

No caso do Município de São Paulo, o padrão de mortalidade segundo causa básica, para o sexo masculino, mostrou a seguinte constituição ${ }^{33}$ :

1. lugar: doença isquêmica do coração, com $17,8 \%$;

2. lugar: neoplasias malignas, com $14,7 \%$;

3. lugar: lesठes vasculares que afetam o sistema nervoso central, com $11,4 \%$;
4. lugar: acidentes de veículos a motor, com $8,3 \%$;

5. lugar: cirrose hepática, $3,6 \%$; outras causas externas, $3,6 \%$;

$6 .^{\circ}$ lugar: outros acidentes, $3,3 \%$;

7. lugar: bronquites, enfisema e asma, $3,1 \%$; doenças hipertensivas, $3,1 \%$

8. lugar: tuberculose, $2,6 \%$.

Para o sexo feminino, no Município de São Paulo, as primeiras quatro causas são as mesmas, porém as neoplasias estão em primeiro lugar, e a doença isquêmica do coração está em 3. lugar ${ }^{33}$.

A Tabela 2 mostra a mortalidade segundo causas e sexo em indiviciuos de 40 a 60 anos, no Município de São Paulo, 1982.

Quando a mortalidade é analisada segundo a causa, mas em todos os grupos etários e no país como um todo, observou-se em 1979 a seguinte distribuição, em ordem decrescente de importância ${ }^{48}$.

1.) Doenças do aparelho circulatório $25,10 \%$

2.) Sintomas, sinais e afecçóes mal definidas........................ $20,15 \%$

3.) Doenças infecciosas e parasitárias . .................... 10,33\%

4.) Causas externas (acidentes, envenenamentos, violências).....

$9,15 \%$

5 .) Neoplasias (todos os tipos)........ $8,14 \%$

6 .) Doenças do aparelho respiratório $8,08 \%$

79.) Causas perinatais....... ..... $7,04 \%$

8.) Doenças das glândulas endócrinas, nutrição, metabolismo e transtornos imunitários.....

$3,54 \%$

9.) Doenças do aparelho digestivo.. $\quad 3,30 \%$

10.) Doenças do aparelho geniturinário. $\cdots$

11.) Doenças do sistema nervoso e órgãos dos sentidos..

TABELA 2

Mor talidade segundo causas e sexo em indivíduos de 40 a 60 anos, Município de São Paulo, 1982.

\begin{tabular}{|c|c|c|c|c|c|}
\hline \multirow{2}{*}{ Causas } & \multicolumn{2}{|c|}{ Homens } & \multirow{2}{*}{ Causas } & \multicolumn{2}{|c|}{ Mulheres } \\
\hline & Nọ & $\%$ & & Nọ & $\%$ \\
\hline Doenças do Coração & 1730 & 22,0 & Tumores Malignos & 1126 & 26,6 \\
\hline Tumores Malignos & 1298 & 16,5 & Doenças do Coração & 693 & 16,4 \\
\hline Causas Externas & 1078 & 13,7 & Doenças do Cérebro & 646 & 15,3 \\
\hline $\begin{array}{l}\text { Doenças Cérebro- } \\
\text { Vasculares }\end{array}$ & 843 & 10,7 & Causas Externas & 221 & 5,2 \\
\hline Pneumonia & 334 & 4,2 & D. Hipertensivas & 173 & 4,1 \\
\hline Todas as Causas & 7876 & 100,0 & Todas as Causas & 4229 & 100,0 \\
\hline
\end{tabular}

Fonte: Dados da Fundação SEADE, ex traídos de Medina ${ }^{59}$ (1986). 
12.) Anomalisas congênitas

$1,21 \%$

13ㅇ) Doenças do sangue e orgãos hematopoiéticos.................. $0,40 \%$

14.) Complicaçós da gravidez, parto e puerpério..

$\left.15^{\circ}\right)$ Transtornos mentais..

16.) Doenças do sistema osteomuscular e tecido conjuntivo.... ........

179) Doenças da pele e tecido celular subcutâneo.

Como bem salienta Laurenti ${ }^{48}$, a propósito desta lista, "digno de nota é o fato de que as chamadas 'doenças de áreas desenvolvidas' cardiovasculares e neoplasias - situam-se entre as primeiras causas de morte e o nosso pais vêse dessa maneira numa situação paradoxal, pois estas coexistem com as doenças infecciosas ainda importante grupo de causas de morte - e com as mortes sem assistência médica".

A importância das doenças cardiovasculares como causa de morte na população brasileira já vem sendo apontada há mais tempo ${ }^{47,49,77}$. Ambas as listas anteriormente apresentadas coincidem em realçar a importância deste grupo de doenças, tanto como causa de morte na população como um todo, mas principalmente em adultos, e dentre estes, os do sexo masculino, em especial. Por exemplo, através do estudo de Guimarães e col. ${ }^{33}$ observa-se que em adultos masculinos no Município de São Paulo, se forem somadas as mortes devidas à doença isquêmica do coração $(17,8 \%)$, com as devidas a lesões vasculares que afetam o Sistema Nervoso Central (SNC) $(11,4 \%)$ e, ainda, com as doenças hipertensivas $(3,1 \%)$, as doenças cardiovasculares ultrapassarão $32 \%$, ou seja, praticamente $1 / 3$ de todas as mortes. Em adultos acima de 50 anos, a proporção de mortes devidas a doenças cardiovasculares aproxima-se dos $55 \%$ s1.

As neoplasias malignas despontam como a segunda causa de morte em adultos masculinos e a primeira em adultos do sexo feminino, a julgar pelos dados de 1979, relativos ao Município de São Paulo ${ }^{33}$. Entre as causas de morte na população geral, em todas as faixas etárias, as neoplasias ocupam o quinto lugar ${ }^{48}$. A importância das neoplasias como causa de morte pode também ser avaliada pela tendência de crescimento do problema. Assim, Pastorelo ${ }^{74}$, em 1980, ao comparar a mortalidade por câncer no distrito de São Paulo, observada no período $1962 / 63$ com aquela no período $1974 / 75$, concluiu que $o$ risco de morte por todas as localizações de câncer, para o sexo masculino, foi maior no período de $1974 / 75$, em todos os grupos etários, exceto no de 15-24 anos. O sexo fe- minino, igualmente, teve seu risco de morte, por todas as localizações de câncer, aumentado naquele mesmo periodo, nos grupos etários de 15 a 24 anos, de 35 a 44 anos e de 45 a 54 anos. Conclui Pastorelo" que "tanto para o sexo masculino, quanto para o sexo feminino, de uma maneira geral, o grande incremento da mortalidade por câncer ocorreu nas coortes mais jovens".

Diferentes indicadores coincidem em mostrar a extraordinária importância das mortes por causas violentas, tanto a nível do país como um todo, como a nível das áreas metropolitanas. Para a população geral do Brasil, em todas as faixas etárias, as causas externas (acidentes, envenamentos, violências) são responsáveis por $9,15 \%$ de todas as mortes ${ }^{48}$. Em adultos na faixa etária de 15 a 74 anos, após as doenças cardiovasculares (doença isquêmica do coração + lesठ̃es vasculares que afetam o SNC) e o câncer, aparecem as mortes por acidentes de veículos a motor, responsáveis por $8,3 \%$ dos óbitos nessa faixa etária. Somem-se a eles, as mortes por outras causas externas, com $3,6 \%$ e os outros acidentes, com $3,3 \%$, o que totaliza $15,2 \%{ }^{33}$.

Como já mencionamos anteriormente, Mello Jorge ${ }^{60,61}$ dedicou-se ao estudo epidemiológico das mortes violentas no Município de São Paulo. Entre outros achados de importância, verificou que, no período de 1960 a 1975, o risco de morrer por essas causas elevou-se de 44,11 para 59,20 por 100 mil habitantes; naquele período as mortes violentas corresponderam a $8 \%$ da mortalidade geral no Município de São Paulo60,61. A avaliação da situação em 1980, confirmou a gravidade do problema ${ }^{62}$.

Em Fortaleza-CE, Silva ${ }^{93}$ verificou que as mortes violentas ocupam o primeiro lugar quanto aos anos potenciais de vida perdidos (APVP).

Utilizando as tábuas de vida de múltiplo decremento, Gotlieb ${ }^{31}$ confirmou a importância dos acidentes, dos envenamentos e das violências, na composição da mortalidade no Município de São Paulo.

Deixando de lado os comentários sobre todas as outras causas importantes de morte, destacamos, os três primeiros grupos de causas de morte de adultos no Brasil - doenças cardiovasculares, câncer e mortes violentas - que juntos significam praticamente $60 \%$ de todos os óbitos nessa faixa etária - padrão não muito diferente do que ocorre nas regiסes do globo mais desenvolvidas. Cabe, então, a pergunta - Qual o peso, qual a força da contribuição indireta da ocupação na determinaçāo dessas grandes causas de morte?

Será difícil, ou melhor, impossível respondê- 
la com precisão. Aliás, nem na Inglaterra nem na Finlândia, onde existem as melhores estatísticas vitais do mundo, esta pergunta poderá ser respondida com exatidão. Contudo, alguns indicadores serão mencionados, ainda que incompletos e suscetíveis a viéses metodológicos. Eles permitem inferir, de um modo geral, ser significativo o "peso" ou a "força" dessa contribuição, entendidos dentro de um contexto de "competição de riscos", conforme já discutido.

\section{Doenças cardiovasculares}

O estudo da contribuição da ocupação na produção de doenças cardiovasculares constitui uma das áreas que muito têm atraído pesquisadores nos últimos anos, a julgar pela quantidade de trabalhos que aparecem na literatura científica. Seria impossível nesse curto espaço revisar a extensa literatura sobre o tema, principalmente porque outros o fizeram, recentemente, com muita propriedade $34,45,87,88$.

Em relação à aterosclerose, acredita-se que apesar de serem relativamente bem conhecidos os principais fatores de risco (idade, colesterol sérico, pressão arterial, tabagismo, e outros), esses fatores já conhecidos responderiam por não mais de $50 \%$ da gênese do problema, restando ainda um outro tanto para ser adequadamente desvendado ${ }^{88}$.

Assim, além do estresse, importante no problema da hipertensão arterial e já discutido quanto aos seus vínculos com o trabalho, podem ser mencionados alguns riscos ocupacionais específicos, principalmente riscos químicos que crescentemente vêm despertando o interesse dos pesquisadores, quer a nível de toxicologia experimental, quer na observação clínica de casos geralmente agudos, quer a partir de estudos epidemiológicos de mortalidade, principalmente acompanhando coortes de trabalhadores expostos a determinados agentes e/ou engajados em determinados ramos de atividade.

Por exemplo, já de longa data vem sendo enfocado o problema da exposição ambiental/ ocupacional ao monóxido de carbono $(\mathrm{CO})$. É verdade que o componente ocupacional deste risco é mascarado no caso de fumantes, e embora existam evidências experimentais que sugerem efeito aterosclerótico de exposiçōes prolongadas a concentrações relativamente baixas, estudos de coortes de trabalhadores são ainda insuficientes para dar fundamento definitivo a essas observaçð̃es. Contudo, tem sido fartamente documentado através de casos clínicos, que indivíduos com insuficiência coronariana crônica ou insuficiência vascular periférica têm seus sintomas agravados em situaçóes que os expõem a concentrações elevadas de CO. Estas observações clínicas isoladas têm sido confirmadas em estudos de coortes de trabalhadores expostos a situações críticas em relação ao monóxido de carbono $3,17,30,36,44,88,108$.

A exposição ocupacional a nitratos organicos na fabricação e manipulação de explosivos tem sido associada ao desencadeamento de episódios agudos de angina do peito, de infarto do miocárdio e de morte súbita de trabalhadores. O mecanismo de ação mais freqüentemente mencionado é o da "abstinência" súbita, ou seja, a interrupção brusca da exposição aos nitroglicóis, o que provocaria um vaso-espasmo coronariano, já descrito como "morte das segundas-feiras de manhä', devido à latência de 36$72 \mathrm{~h}$. Trabalhadores expostos a nitroglicerina e a etileno-glicol, durante mais de 20 anos, mostraram que o risco de morrer por doenças cardiovasculares aumentou 2,5 vezes $8,39,40,46,56,66$.

Exemplo dos mais importantes em termos de toxicologia industrial é o sulfeto de carbono $\left(\mathrm{CS}_{2}\right)$. Na evolução histórica da doença relacionada à exposição ao sulfeto de carbono, as primeiras observações mostraram que altas concentraçōes, a curto prazo, provocam quadros mentais graves, do tipo psicótico; posteriormente baixas concentraçðes, a médio prazo, foram associadas à produção de polineurites; e com as medidas de higiene industrial adotadas a partir da Segunda Guerra Mundial, principalmente em países europeus, exposições a longo prazo, a baixas concentraçðes (20 a $40 \mathrm{ppm})$, mostraram-se associadas a ef eitos vasculares difusos, assemelhando-se morfologicamente à aterosclerose provocada pela idade ${ }^{110 *}$.

Com efeito, todos os estudos de mortalidade de trabalhadores expostos ao sulfeto de carbono, realizados a partir da década de 60 , revelaram um excesso de mortalidade por doenças cardiovasculares, especialmente a doença isquêmica do coração. No Reino Unido, Tiller e col..$^{97}$ observaram um excesso de mortalidade de 2,5 vezes em trabalhadores da indústria do rayon pelo processo viscose, expostos dez ou mais anos; as doenças cardiovasculares foram responsáveis por $42 \%$ das mortes entre os expostos, enquanto que apenas $24 \%$ dos controles da mesma empresa morreram devido a essas doenças. Os melhores estudos nesse campo vêm dos finlandeses que desde 1967 acompanham a mortalidade de trabalhadores expostos ao $\mathrm{CS}_{2}$,

\footnotetext{
* No Brasil, as informações sobre o problema do sulfeto de carbono em trabalhdores devem ser creditadas a Ribeiro e $\mathrm{col}^{84}$, a Florence ${ }^{29}$, e, mais recentemente, a Rodrigues e Maranhāo ${ }^{85}$.
} 
principalmente na indústria do rayon. Assim, os primeiros estudos com uma coorte seguida durante cinco anos, mostraram um risco de 4,7 vezes de morrer por doença isquêmica do coração, comparando-se expostos com controles. Simultaneamente, detectaram um excesso de prevalência de angina do peito, de níveis elevados de pressão arterial, e de alteraçðes eletrocardiográficas ${ }^{35}$. Ao fim de oito anos de seguimento da mesma coorte de trabalhadores, a incidência acumulada de morte por doença coronariana era de $5,8 \%$ entre os expostos e $2,6 \%$ entre os controles ${ }^{99}$. Com as medidas de controle ambiental, que viabilizaram a progressiva redução da concentração de $\mathrm{CS}_{2}$ de $\mathbf{3 0 - 4 0}$ ppm, como ocorria na década de 50 , para menos de $10 \mathrm{ppm}$ na década de 70 , houve um reflexo favorável sobre a morbidade e a mortalidade cardiovascular, em especial sobre a incidência de infarto do miocárdio e a ocorrência de angina do peito $68,69,100$.

Recente documento da Organização Mundial da Saúde ${ }^{110}$, ao resumir os efeitos da exposição ao sulfeto de carbono no que se refere aos efeitos cardiovasculares, concluiu que os estudos realizados em vários países (Finlândia, Noruega e Reino Unido são mencionados), "mostram que o $\mathrm{CS}_{2}$ promove o desenvolvimento de doença isquêmica coronariana, e que a exposição a níveis de 30 a $120 \mathrm{mg} / \mathrm{m}^{3}$ por mais de dez anos, parece aumentar o risco de doença coronariana"'110.

O estudo de mortalidade de trabalhadores de fundiçðes de cobre, expostos ao arsênico, mostrou um excesso de 2,2 vezes, nas mortes por doença cardiovascular ${ }^{4}$. Esses encontros poderiam estar relacionados com a vasculopatia periférica observável no hidroasenicismo crônico, endêmico no norte do México, e em regiōes do Chile e da Argentina ${ }^{32}$.

Um outro ângulo de observação da força da ocupação sobre a mortalidade por doenças cardiovasculares, é a utilização da Razão de Mortalidade Padronizada (RMP ou SMR), procedimento que facilita a visualização do excesso de risco. Entre outros, o trabalho de Karvonen ${ }^{42}$ ilustra bem o valor deste parâmetro, ao analisar os óbitos por doenças cardiovasculares em adultos masculinos na Finlândia, segundo grupo ocupacional. Timio ${ }^{98}$ analisa a mortalidade de outros países, agrupando os trabalhadores segundo classe social.

\section{Câncer}

Como jà foi visto, o câncer situa-se entre as principais causas de morte na população brasileira, ocupando o segundo lugar na mortalida- de de adultos, onde ele é responsável por cerca de $15 \%$ de todas as mortes ${ }^{33}$. Assim, não é sem razão que se busca conhecer mais detalhadamente algumas de suas características epidemiológicas, mesmo porque, apesar de sua etiologia, globalmente, continuar a desafiar a ciência médica, importantes avanços já foram obtidos na elucidação das causas do câncer, ou melhor, dos fatores de risco envolvidos na sua produção.

O conhecimento dos fatores de risco relacionados com a etiologia do câncer permite, em princípio, que se trabalhe em sua prevenção, isto é, interceptando ou eliminando esses fatores de risco. Esta parcela do problema do câncer passível de prevenção ou eliminação é, às vezes, referida como fração evitável. Esta tende a crescer dia a dia, o que faz com que aumentem consideravelmente as chances de reverter o quadro sanitário provocado pelo câncer, como aliás já vem sendo conseguido nos países desenvolvidos, por meio da redução do tabagismo e a consequiente redução da incidência do câncer de pulmão ${ }^{18}$.

Com esta compreensão, busca-se avidamente detectar causas ou fatores de risco, e a maior parte destes situa-se ou nos assim chamados $f a$ tores ambientais, ou no estilo de vida - ambos os grupos compreensivelmente suscetíveis às mais diferentes acepçőes, interpretaçōes e viéses. Já em 1964, um grupo de especialistas da Organização Mundial da Saúde ${ }^{111}$ assim se manifestava a respeito da questão: "A factibilidade da prevenção do câncer está limitada pela proporção de câncer humano em que fatores extrínsecos são responsáveis. Estes [fatores] incluem todos os carcinógenos ambientais (quer tenham sido identificados, ou não), assim como os 'fatores modificadores' que favorecem [0 aparecimento de] neoplasias de causas aparentemente intrínsecas (por exemplo, alteraçð̃es hormonais, deficiências nutritivas, e defeitos metabólicos). Estas categorias de câncer que são influenciadas, direta ou indiretamente, por fatores extrínsecos, incluem os tumores de pele e de boca, os tumores dos tratos respiratório, gastrintgestinal e urinário, os tumores hormônio-dependentes (tais como o de mama, de tireóide e de útero), os do sistema hematopoiético e linfopoiético, os quais, coletivamente, significam mais de $3 / 4$ dos cânceres humanos. $P a$ rece, portanto, que a maior parte do câncer humano é potencialmente prevenivel" '(grifo nosso).

A partir de então, muitos têm se aventurado na tentativa de estimar qual seria a fração efetivamente prevenível, e principalmente aquela devida a fatores ambientais, como se expressou 
- grupo de especialistas da OMS"1'. Esses exercícios, especulativos às vezes, fizeram com que se chegasse a cifras tão elevadas quanto 80 ou $90 \%$, e com frequência esses números săo mencionados. E verdade que dentro desta fração está incluída a proporção de cânceres devidos ao tabagismo, e como já tem sido exaustivamente estudado, a eliminação do hábito de fumar, por si só, reduziria de $1 / 3$ a mortalidade por câncer, quando todos os tipos e localizaçōes são considerados juntos ${ }^{19}$.

A possibilidade de evitar câncer, isto é, a evitabilidade (avoidability) é reforçada pelos estudos epidemiológicos que demonstram diferenças marcantes na incidência de câncer, quando diferentes comunidades ou regið̄es são comparadas, ou então quando a incidência entre os que emigram de uma região para outra torna-se progressivamente diferente daquela que ocorre em sua região de origem. A análise das tendências seculares do câncer em alguns países ou regióes reforça a idéia da influência de fatores extrínsecos envolvidos na produção dos tumores malignos.

Em tal contexto, é compreensível que se busque conhecer a influência de riscos ocupacionais na causação do câncer, $e$, naturalmente, tal conhecimento poderá nortear os esforços para reduzir ou eliminar da fração evitável a parte ocupacionalmente determinada. Como é sabido, há mais de 200 anos vêm sendo descritos os efeitos carcinogênicos relacionados a atividades profissionais. Coube a Percivall Pott, em 1775, estabelecer o nexo causal entre a atividade de limpeza de chaminés, exercida por meninos adolescentes, e o aparecimento, após muitos anos, do câncer de escroto ${ }^{107}$. Passados mais de 150 anos, Cook e col.13 identificaram o benzo(alfa)pireno como o poderoso carcinógeno responsável pelos tumores descritos, e aliás, por outros tantos, de localização diversa. Essas observaçðes, reforçadas pelos clássicos estudos sobre câncer de bexiga em trabalhadores que manipulavam anilinas ${ }^{9}$, desencadearam estudos no mundo inteiro, que progressivamente resultaram em achados cada vez mais numerosos, sobre riscos ocupacionais associados à produção de neoplasias malignas.

Das extensas listas de produtos ou processos industriais potencialmente carcinogênicos, existe consenso em torno de aproximadamente sete processos industriais e cerca de 20 substâncias químicas de origem ocupacional, que a Agência Internacional para Pesquisa do Câncer (IARC), ligada à Organização Mundial da Saúde, classifica no assim chamdo grupo $1^{41}$.
A Tabela 3, organizada a partir das mais recentes revisoes sobre o problema 22,41,63,65,73,89,91,101, resume a lista de agentes químicos de origem ocupacional, e/ou processos industriais considerados carcinogênicos para trabalhadores.

Assim, com agentes cancerígenos e processos industriais tão diversificados e numerosos, é compreensível a curiosidade, ou seja, o interesse prático de se conhecer qual a fração de todos os cânceres que deve ser debitada diretamente na conta da ocupação. Seria possível assim, tentar mobilizar os arsenais da tecnologia de métodos e processo, da higiene industrial, da medicina do trabalho e da legislação de saúde ocupacional, no sentido de minimizar ou eliminar esta fração, e assim assegurar a saúde dos trabalhadores, pelo menos no que diz respeito a esta causa de doença e morte.

Com efeito, muitas têm sido as tentativas de obter tais estimativas, e as enormes diferenças obtidas entre os resultados desses exercícios refletem não somente a diversidade de critérios sobre o que é risco ocupacional (a radiação ultravioleta de origem solar, que provoca câncer de pele em agricultores ou em pescadores? $O$ câncer cérvico-uterino em prostitutas?), como também aspectos metodológicos sobre dose e tempo de exposição. Adicionalmente, entram em cena fortes influências de posturas ideológicas e políticas, que vão desde a insistência de uns em querer mostrar a inocuidade universal dos produtos químicos, até posturas apocalípticas que vêem em tudo motivo de preocupação e desconfiança, que chegam ao limite da obsessão.

Entre as estimativas mais vezes mencionadas, situam-se as de Higginson e Muir ${ }^{37,38}$, e de Wynder e $\mathrm{Gori}^{112}$, os quais sugerem que aproximadamente $5 \%$ de todos os cânceres seriam devidos a riscos ocupacionais. Cole ${ }^{11}$ estima em cerca de $10 \%$ e Doll e Peto ${ }^{20,21}$, muitas vezes citados, estimam em $4 \%$. Muita celeuma produziram recentemente as estimativas feitas por Bridbord e col.', segundo as quais 23 a $38 \%$ de todos os cânceres seriam devidos a riscos ocupacionais.

Na verdade, o trabalho de Bridbord e col. ${ }^{7}$ é um documento produzido conjuntamente pelo Instituto Nacional do Câncer (NCI), pelo Instituto Nacional de Ciências Ambientais da Saúde (NIEHS) e pelo Instituto Nacional de Seguranca e Saúde Ocupacional (NIOSH); dos Estados Unidos - trabalho que se tornou conhecido como Documento da OSHA; de 1978*. Segundo Doll e Peto ${ }^{20,21}$, a elevada proporção obtida pelos pesquisadores ${ }^{7}$ teria sido conseguida através

* Por ter sido adotado pela Administração de Segurança e Saúde Ocupacional - OSHA, naquela época. 
TABELA 3

Principais cancerígenos ocupacionais conhecidos.

\begin{tabular}{|c|c|c|}
\hline Agente/Processo & Orgão-alvo & Comentários \\
\hline 1-Aminobifenila & Bexiga & $\begin{array}{l}\text { No passado, utilizado como anti-oxidante da borracha } \\
\text { e como in termediário de corrantes. }\end{array}$ \\
\hline $\begin{array}{l}\text { Arsênico (trióxido, arse- } \\
\text { natos e arsenitos). }\end{array}$ & Pele, pulmão & $\begin{array}{l}\text { Acima de } 95 \% \text { do arsênico produzido é um sub-produ to } \\
\text { da fundição de minérios de cobre e minérios de chumbo. } \\
\text { Excesso de câncer de pulmão tem sido observado, asso- } \\
\text { ciado ao uso e produção de pesticidas à base de arsênico } \\
\text { inorgânico trivalente. }\end{array}$ \\
\hline Asbesto & $\begin{array}{l}\text { Pulmão, pleura e peri- } \\
\text { tônio } \\
\text { Laringe } \\
\text { Trato Gastrintestinal }\end{array}$ & $\begin{array}{l}\text { O mais utilizado entre nós é a crisotila. Estima-se que } \\
\text { nos Estados Unidos, ele seja responsável por } 5 \% \text { das } \\
\text { mortes de câncer de pulmão, e } 1-2 \% \text { de todas as mortes } \\
\text { por câncer no homem. }\end{array}$ \\
\hline $\begin{array}{l}\text { Auramina (substâncias } \\
\text { encon tradas em sua } \\
\text { produção). }\end{array}$ & Bexiga & $\begin{array}{l}\text { Utilizada individualmente como corante ou intermediá- } \\
\text { ria de corante, para tingimento de tecidos, couro e } \\
\text { papel. }\end{array}$ \\
\hline Benzeno & $\begin{array}{l}\text { Medula óssea (mais co- } \\
\text { mumente leucemia mie- } \\
\text { lóide agu da) }\end{array}$ & $\begin{array}{l}\text { Utilizado largamente como matéria-prima na indústria } \\
\text { petroquímica, e como solvente, na produção e uso de } \\
\text { tintas, vernizes, colas, "thiners", etc. (Vide a excelente } \\
\text { revisão de Vigliani 106) }\end{array}$ \\
\hline Benzidina & Bexiga & $\begin{array}{l}\text { Aminas aromáticas usadas como intermediários na pro- } \\
\text { dução de corantes. (Trabalho original de Case e col. }{ }^{9} \text { ). }\end{array}$ \\
\hline $\begin{array}{l}\text { Cloroetéres (clorometil } \\
\text { metil eter e bis-cloro- } \\
\text { metil eter) }\end{array}$ & Pulmão & $\begin{array}{l}\text { Utilizado na produção de plásticos, de resinas de troca } \\
\text { iônica, de bactericidas e fungicidas. }\end{array}$ \\
\hline Cloreto de vinila & $\begin{array}{l}\text { Angiossarcoma hepático } \\
\text { Cérebro } \\
\text { Pulmão }\end{array}$ & Monômero utilizado na produção de PVC. \\
\hline $\begin{array}{l}\text { Cromo e seus compo- } \\
\text { nentes }\end{array}$ & $\begin{array}{l}\text { Pulmão } \\
\text { Seios paranasais }\end{array}$ & $\begin{array}{l}\text { Utilizado em ligas metálicas, galvanoplastia, fitas magné- } \\
\text { ticas, pigmentos de tintas, borracha, como oxidante em } \\
\text { reaçōes químicas. }\end{array}$ \\
\hline $\begin{array}{l}\text { Emissōes de fornos de } \\
\text { coque }\end{array}$ & $\begin{array}{l}\text { Pulmão } \\
\text { Trato urinário }\end{array}$ & $\begin{array}{l}\text { Mistura complexa de produtos da combustão e destila- } \\
\text { ção do carvão, contém hidrocarbonetos aromáticos poli- } \\
\text { cíclicos. Sobre a mortalidade por câncer em trabalhado- } \\
\text { res de coquerias em indústrias siderúrgicas, vejam-se os } \\
\text { trabalhos de Redmond e col. }{ }^{82,83} \text { ). }\end{array}$ \\
\hline $\begin{array}{l}\text { Fuligem, alcatrōes, } \\
\text { óleos minerais (incluin- } \\
\text { do creosoto, óleos de } \\
\text { corte e xisto) }\end{array}$ & $\begin{array}{l}\text { Pele } \\
\text { Escroto } \\
\text { Pulmão } \\
\text { Bexiga } \\
\text { Trato gastrintestinal }\end{array}$ & $\begin{array}{l}\text { Estas substâncias derivam dos processos de destilação do } \\
\text { petróleo ou do carvão, e seu risco reside nas misturas de } \\
\text { hidrocarbonetos aromáticos policíclicos, entre os quais, } \\
\text { o benzo (alfa) pireno tem sido o mais exaustivamente } \\
\text { estudado. O risco é đefinido em função da via de expo- } \\
\text { sição/absorção (absorção por pele, inalação, ingestão). } \\
\text { Sobre a mortalidade por câncer em trabalhadores } \\
\text { expostos a névoas de óleo de corte, consultar Decou- } \\
\text { fle }{ }^{15} \text { ) }\end{array}$ \\
\hline Gás mostarda & Bexiga & $\begin{array}{l}\text { O gás mostarda foi utilizado como arma química na } 1 \text { a } \\
\text { Guerra Mundial, e continuou a ser produzido e utilizado } \\
\text { na } 2 \text { a Guerra Mundial. Chegou a ser testado como agen- } \\
\text { te alquilante antineoplásico. Trabalhadores expostos a } \\
\text { longo prazo tiveram a mortalidade por câncer aumen- } \\
\text { tada. }\end{array}$ \\
\hline
\end{tabular}

Continua... 


\begin{tabular}{|c|c|c|}
\hline Agente/Processo & Orgâo-alvo & Comentários \\
\hline 2. Naftilamina & Bexiga & $\begin{array}{l}\text { Utilizada, principalmente como intermediário na produ- } \\
\text { ção de corantes e como anti-oxidante na indústria da } \\
\text { borracha. Sua produção mundial tende a diminuir. (vide } \\
\text { Case e col. }{ }^{9} \text { ). }\end{array}$ \\
\hline $\begin{array}{l}\text { Níquel e compostos de } \\
\text { niquel (operaçōes de } \\
\text { refino) }\end{array}$ & $\begin{array}{l}\text { Pulmão } \\
\text { Vias aéreas superiores } \\
\text { Laringe }\end{array}$ & $\begin{array}{l}\text { Utilizado em galvanoplastia, produção de aço e outras } \\
\text { ligas, cerâmicas, baterias, material elétrico, processos } \\
\text { catalíticos de petróleo, hidrogenação de óleos, etc. }\end{array}$ \\
\hline $\begin{array}{l}\text { Produção de álcool iso- } \\
\text { propílico (processo do } \\
\text { ácido forte) }\end{array}$ & $\begin{array}{l}\text { Seios paranasais } \\
\text { Laringe }\end{array}$ & $\begin{array}{l}\text { A produção de álcool isopropílico pelo processo de } \\
\text { ácido sulfúrico forte deixa um resíduo de óleos isopro- } \\
\text { pílicos, de sulfato di-isopropílico e de sulfato dietílico. } \\
\text { Ainda não está bem esclarecido se a ação carcinogênica } \\
\text { sobre o trato respiratório deve-se a uma ou a mais destas } \\
\text { substâncias. Os principais usos comerciais de álcool } \\
\text { isopropílico são na produção de acetona, ou como sol- } \\
\text { vente ou substância química intermediária. }\end{array}$ \\
\hline $\begin{array}{l}\text { Trabalhadores da indús- } \\
\text { tria de móveis de madeira }\end{array}$ & $\begin{array}{l}\text { Nariz (adenocarcinoma } \\
\text { do epitélio nasal) }\end{array}$ & $\begin{array}{l}\text { Exposiçāo a poeira (serragem). Para uma discussão } \\
\text { mais aprofundada, consultar a revisão feita por } \\
\text { Wills }{ }^{109} \text {. }\end{array}$ \\
\hline $\begin{array}{l}\text { Trabalhadores da indús- } \\
\text { tria do couro }\end{array}$ & Bexiga & Consultar Decoufle $e^{16}$ \\
\hline $\begin{array}{l}\text { Trabalhadores da indús- } \\
\text { tria da borracha }\end{array}$ & $\begin{array}{l}\text { Pulmão } \\
\text { Trato gastrintestinal } \\
\text { Cérebro } \\
\text { Bexiga } \\
\text { Pele } \\
\text { Leucemia } \\
\text { Linfoma }\end{array}$ & $\begin{array}{l}\text { Consultar Parkes e col. }{ }^{73} \text { McMichael e col. }{ }^{58} \text { e Monson e } \\
\text { Fine }\end{array}$ \\
\hline
\end{tabular}

de estimativas e tratamentos estatísticos inadequados. Aliás, referindo-se àquele trabalho ${ }^{7}$, Doll e Peto ${ }^{20,21}$, de modo desabrido, afirmam que "os autores assim o fizeram com propósitos mais políticos que cintíficos (...), para enfatizar a importância dos riscos ocupacionais (...) visando impressionar as autoridades do país, assim como impressionar a imprensa leiga e os meios de divulgação científica. (...) Gostaríamos de sugerir que este 'trabalho da OSHA' não fosse considerado como uma contribuição séria para o pensamento científico, e nem deveria ser citado ou utilizado como se fosse sério"20,21. A controvérsia prossegue, e Bridbord e col. ${ }^{7}$ revisaram recentemente seu estudo ${ }^{14}$, tentando demonstrar as razoes das profundas diferenças entre seus dados e os mais comumente aceitos.

Contudo, apesar das divergências nesse campo, e preferindo esposar a postura mais cautelosa e elaborada que Doll e Peto ${ }^{20,21}$, com muito cuidado desenvolvem, considerou-se oportuno, para as finalidades desta revisão, mencionar as fraçōes de câncer atribuiveis à ocupação, segundo a localização e/ou o tipo de tumor, para, inclusive, entender como aqueles autores chegaram à estimativa de $4 \%$ para todos os cânceres.
Isto permitiria, em princípio, fazer o mesmo exercício que aqueles autores fizeram, aplicando sua metodologia às estatísticas brasileiras, $e$ com isto, chegar próximo ao número de casos de morte por câncer que poderiam ser evitadas, no correr de um ano, se os riscos ocupacionais fossem adequadamente controlados, ou melhor, definitivamente eliminados.

Nesta direção, Doll e Peto ${ }^{20,21}$ agruparam as diferentes localizações e os diferentes tipos de tumores malignos em três grupos, a saber: um constituído dos tumores malignos que não guardam relação com a ocupação, à luz dos conhecimentos atuais; outro grupo dos que possivelmente poderiam ser produzidos por riscos ocupacionais, e, finalmente, o grupo dos que com certeza podem ser produzidos por riscos ocupacionais. As Tabelas 4 e 5 listam os dois primeiros grupos.

O nexo causal entre os tumores listados na Tabela 5 e a ocupação é considerado como ainda fraco e inconclusivo, razão pela qual Doll e Peto ${ }^{20,21}$ estimam que $1 \%$ desses tumores em homens, e 0,5\% deles em mulheres, poderiam ser debitados aos riscos ocupacionais.

Contudo, para uma considerável variedade de localizaçð̃es e/ou tipos de tumores existem 
TABELA 4

Cânceres que não são conhecidos como causados por riscos ocupacionais (adaptado de Doll e Peto 20,21 )

\begin{tabular}{l}
\hline Tipo ou localização de câncer ${ }^{\bar{*}}$ \\
\hline Lábio \\
Língua \\
Faringe \\
Intestino delgado \\
Vesícula biliar e vias biliares \\
Melanoma ${ }^{* *}$ \\
Mama \\
Colo do útero \\
Outros cânceres uterinos \\
Ovário \\
Outros órgãos genitais femininos \\
Outros genitais masculinos \\
que não próstata \\
Olho \\
Tireóide \\
Mieloma
\end{tabular}

* Excluindo a luz ultravioleta e as radiaçōes ionizantes.

** Considerando que representa $70 \%$ de todas as mortes por câncer de pele. Algumas ocupaçōes em ambientes ao ar livre têm sido recentemente associadas com discre to aumento do risco de melanoma.

TABELA 5

Cânceres que possivelmente podem ser produzidos por riscos ocupacionais (adaptado de Doll e Peto ${ }^{20,21}$ )

Tipo ou localização do câncer

Boca
Esôfago
Cólon e reto
Pâncreas
Tecido conjuntivo
Rim
Cérebro
Doença de Hodgkin
Linfoma, não do
$\quad$ tipo Hodgkin

sólidas evidências da influência da ocupação em sua causação. Entre os tumores cujo nexo causal com a ocupação tem sido bem estudado, situa-se o câncer de bexiga. Exposiçøes ocupacionais em atividades de alto risco na indústria têm sido responsabilizadas, seguindo vários autores, por $18 \%$ dos $\operatorname{casos}^{12}, 34 \% \%^{104}$ ou $35 \%{ }^{63}$, sempre em adultos masculinos. Cole ${ }^{10}$ sugeriu que $23 \%$ dos casos de câncer de bexiga, em populaçōes na faixa etária de 20 a 59 anos, podem ser atribuídos a riscos ocupacionais, enquanto que esta proporção, em populações de 75 a 89 anos, cai para $7 \%$. Em mulheres estas proporç̃es são bem menores, e têm sido estimadas entre 1 a $6 \%{ }^{10,62}$. Doll e Peto ${ }^{20,21}$ propõem para fins de estimativa da força da ocupação na produção do câncer de bexiga, a adoção de $10 \%$ para homens e $5 \%$ para mulheres.

Em relação ao câncer de pulmão, é grande a contribuição da ocupação em sua etiologia. O asbesto, principal cancerígeno de pulmão, é considerado como responsável por cerca de $5 \%$ de todos os cânceres de pulmão que atualmente ocorrem (pelo menos em países industrializados). Estima-se que a exposição a produtos de combustão do carvão mineral e de derivados do petróleo são responsáveis por outros $5 \%$ de todos os casos de câncer de pulmão em homens. Estas contribuições, somadas à de outros tantos agentes conhecidos, permitiriam estimar em cerca de $15 \%$ de todos os casos em homens, $e$ $5 \%$ dos casos em mulheres ${ }^{20,21}$.

Baseados nestas estimativas mencionadas e em diversos outros estudos compulsados na literatura científica, Doll e Peto ${ }^{20,21}$ elaboraram uma tabela, a que reproduzimos com adaptaçôes (Tabela 6), por meio da qual estimaram o número provável de casos de câncer atribuíveis à ocupação, nos Estados Unidos, para o ano de 1978. Foi através da utilização daquela tabela, combinado com aquela proporção antes mencionada para o grupo de tumores fracamente relacionados com a ocupação, que os autores chegaram aos $4 \%$ como contribuição da ocupação na casuística total de câncer. Os próprios autores recomendam que em outros países esta proporção seja reduzida para 2 ou $3 \%$. Mesmo assim, e dada a importância do câncer como causa de morte, em números absolutos, esta contribuição, no caso do Brasil, já deve estar alcançando alguns milhares de casos por ano etiologicamente associados à ocupação.

A utilização da "Razão de Mortalidade Padronizada" - RMP (SMR em inglês), constitui um enfoque alternantivo para medir a "força" da ocupação na mortalidade por câncer. Sua utilidade e forma de calcular já foram anteriormente descritas.

Apenas para ilustrar esta forma de tratar os dados, reproduziremos os dados obtidos por McMichael e col, ${ }^{58}$, conseguidos a partir do estudo da mortalidade de uma coorte de trabalhadores da indústria da borracha, de 40 a 84 anos de idade, acompanhada durante 10 anos.

Levados em conta os intervalos de confiança, é possível observar um expressivo excesso de mortes por câncer do estômago, da próstata, por linfossarcoma e Hodgkin, e do sistema hematopoiético (além de outras doenças não neoplásicas). Este excesso de risco traduz a idéia de risco atribuível, isto é, os casos que estão acima da linha básica (casos esperados) podem ser considerados atribuiveis ao fato de trabalhar ou ter trabalhado em indústria da borracha, ainda que não se conheçam, necessariamente, os agentes químicos considerados cancerígenos.

Em síntese, este estudo consituiu-se num 
exercício de quantificação do impacto da ocupação enquanto causa direta ou indireta de doença e morte de trabalhadores, no atual contexto das relaçóes entre trabalho e saúde no Brasil. O peso e a complexidade das repercussões sobre o setor saúde obrigam-no a interessar-se pelo problema - interesse que pressupóe papel muito mais ativo na definição de políticas e responsabilidades e na organização de ações destinadas a identificar, reduzir ou eliminar a participação dos riscos ocupacionais nas grandes causas de doença e morte.

TABELA 6

Cânceres que podem ser produzidos por riscos ocupacionais (adaptado de Doll e Peto ${ }^{20,21}$ ).

\begin{tabular}{lcc}
\hline Localização ou tipo & \multicolumn{2}{c}{$\begin{array}{c}\text { Estimativa da proporção } \\
\text { atribuível à ocupação }\end{array}$} \\
\cline { 2 - 3 } & Homens & Mulheres \\
\hline Mesentério e peritônio* & $15 \%$ & $5 \%$ \\
Fígado** e vias biliares extra-hepáticas & $4 \%$ & $1 \%$ \\
Laringe & $2 \%$ & $1 \%$ \\
Pulmão** *** & $15 \%$ & $5 \%$ \\
Pleura, seios paranasais e outras localizaçóes do aparelho respiratório & $25 \%$ & $5 \%$ \\
Osso** & $4 \%$ & $1 \%$ \\
Pele, outros que melanoma & $10 \%$ & $2 \%$ \\
Próstata & $1 \%$ & -5 \\
Bexiga & $10 \%$ & $5 \%$ \\
Leucemia & $10 \%$ & $5 \%$ \\
Cânceres outros não especificados**** & $6,8 \%$ & $1,2 \%$ \\
\hline
\end{tabular}

* Inclui mesotelioma de peritônio, e também câncer "de localização digestiva inespecifica".

** Inclui diversos cânceres secundários de outras localizaçőes, imprecisamente diagnosticados.

*** Implícita a inclusão de casos de mesotelioma de pleura inadequadamente rotulados ou comunicados.

**** Principalmente inespecíficos.

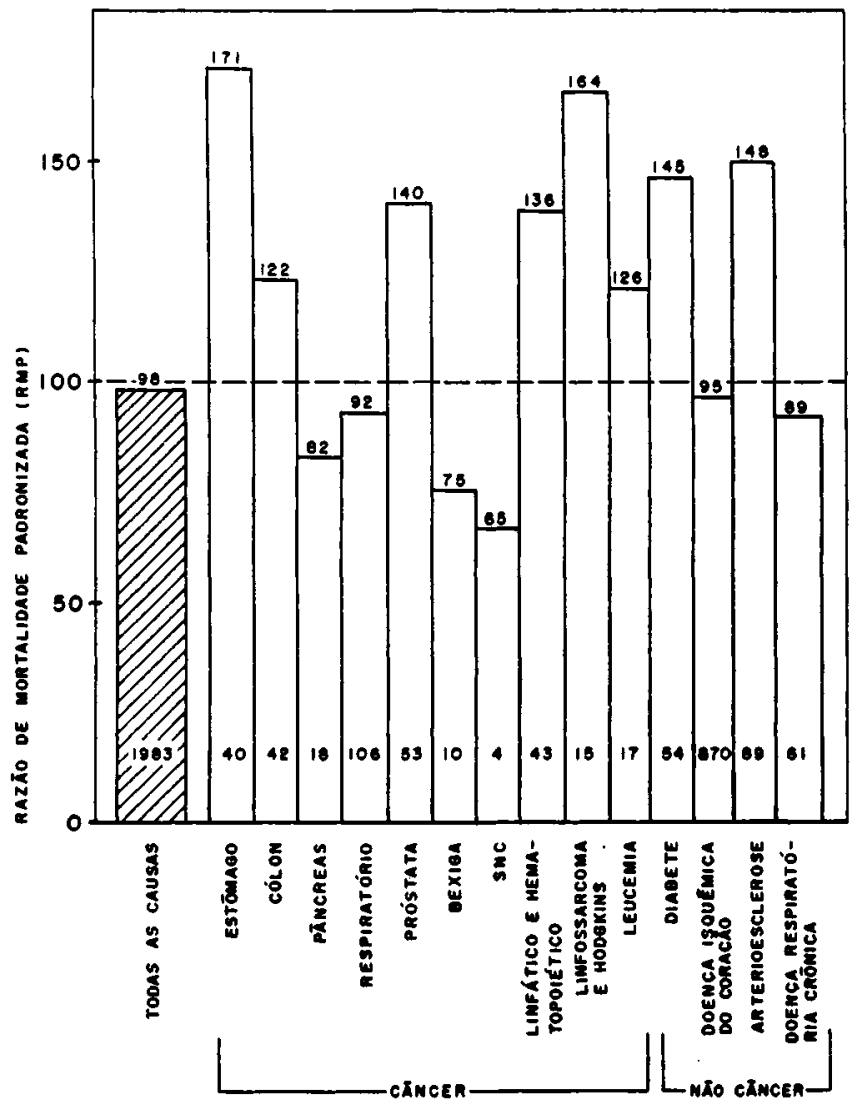

Figura - Razão de mortalidade padronizada (RMP) na população de 6.678 trabalhadores da indústria da borracha, de 1964 a 1973 , de 40 a 84 anos de idade. (Extraído de McMichel e $\operatorname{col}^{58}$ ). 
Mendes, R. [The impact of occupation on worker's health. II - Mortality]. Rev. Saúde públ., S. Paulo, 22:441-57, 1988 .

ABSTRACT: An attempt to estimate the impact of occupation on worker's health was made as part of the rationale for the progressive integration of Occupational Health into the Health Sector. In this second study, based on a critical review of the literature, the repercussions on mortality are discussed on this basis analysis of the Brazilian data on deaths directly related to occupation (fatal occupational accidents and acute poisonings), as well as on those indirectly so related. The analysis of the major causes of adult deaths - cardiovascular diseases, cancer and violent deaths - compared with the proportion of "work-relatedness" according to several epidemiologic studies carried out in developed countries, make possible an estimation of the influence of the contribution of occupation on mortality. The size of this contribution is the main argument for an active involvement of the health sector in Occupational Health issues, because of the heavy toll in terms of adult morbidity and mortality exacted on industrialized societies.

UNITERMS: Occupational mortality. Working risks. Occupational health. Health surveys.

\section{REFERÊNCIAS BIBLIOGRÁFICAS}

1. ALMEIDA, W.F. et al. Intoxicaçðes profissionais por pesticidas. In: Mendes, R., ed. Medicina do trabalho. Doenças profissionais. São Paulo, Sarvier, 1980. p.511-69.

2. ALVAREZ, C.A. \& COLLER, C.D. Los accidentes de transito: cresciente problema para la salud publica. Bol. Ofic. sanit. panamer., 83:310-8, 1977.

3. ANDERSON, E.W. et al. Effects of low-level carbon monoxide exposure on onset and duration of angina pectoris. Ann. intern. Med., 79:46-50, 1973.

4. AXELSON, O. et al. Arsenic exposure and mortality: a case-referent study from a Swedish copper smelter. Brit. J. industr. Med., 35(1):8-15, 1978.

5. BAKER, S.P. Pedestrian deaths in Rio de Janeiro and Baltimore. Accid. Anal. Prev., 9:113-8, 1977.

6. BAKER, S.P. et al. Fatal occupational injuries. $J$. Amer. med. Ass., 248:692-7, 1982.

7. BRIDBORD, K. et al. Estimates of the fraction of cancer in the United States related to occupational factors. Bethesda, Md, National Cancer Institute/ National Institute of Environmental Health Sciences/National Institute for Occupacional Safety and Health, 1978.

8. CARMICHAEL, P. \& LIEBEN, J. Sudden death in explosives workers. Arch. environ. Hlth, 7:424-39, 1963.

9. CASE, R.A.M. et al. Tumours of the urinary bladder in workmen engaged in the manufacture and use of certain dyestuff intermediates in the British chemical industry. Part I - The role of aniline, benzidine, alpha-naphthylamine and beta-naphthylamine. Brit. J. industr. Med., 11:75-104, 1954.

10. COLE, P. A population-based study of bladder cancer. In: Doll, R. \& Vodopija, I., eds. Host environment interactions in the etiology of cancer in man. Lyon, International Agency for Research on Cancer, 1973. p.83-7.

11. COLE, P. Cancer and occupation: status and needs of epidemiologic research. Cancer, 39:1788-91, 1977.

12. COLE, P. et al. Occupation and cancer of the lower urinary tract. Cancer, 29:1250-60, 1972.

13. COOK, J.W. et al. The isolation of a cancerproducing hydrocarbon from coal tar. J. chem. Soc., 1:395-405, 1933.

14. DAVIS, D.L. et al. Cancer prevention: assessing causes, exposures, and recent trends in mortality for U.S. males, 1968-1978. Int. J. Hlth Serv, 13:337-72, 1983.

15. DECOUFLE, P. Cancer mortality among workers exposed to cutting-oil mist. Ann. N.Y. Acad. Sci., 271:94-101, 1976.

16. DECOUFLE, P. Cancer risks associated with employment in the leather and leather products industry. Arch. environ. Hlth, 34:33-7, 1979.

17. DECOUfLE, P. et al. Mortality by cause among stationary engineers and stationary firemen. $J . o c$ cup. Med., 19:679-82, 1977.

18. DOLL, R. Relevance of epidemiology to policies for the prevention of cancer. J. occup. Med., 23:601-9, 1981.

19. DOLL, R. Prospects for prevention. Brit. med. J., 286:445-53, 1983.

20. DOLL, R. \& PETO, R. The causes of cancer: quantitative estimates of avoidable risk of cancer in the United States today. J. Nat. Cancer Inst. 66:1191-265, 1981.

21. DOLL, R. \& PETO, R. The causes of cancer: quantitative estimates of avoidable risks of cancer in the United States today. Oxford, Oxford University Press, 1981.

22. ERNST, P \& THERIAULT, G. Known occupational carcinogens and their significance. Canad. med. Ass. J., 130:863-7, 1984.

23. FARIA, M.A.M. et al. Saúde e trabalho: acidentes de trabalho em Cubatão. Rev. bras. Saúde ocup., 11(42):7-26, 1983

24. FARIA, M.A.M. et al. Alguns aspectos sociais relacionados à ocorrência de acidentes do trabalho em municipio industrial: o caso de Cubatão. Rev. bras. Saude ocup., 11(43):25-35, 1983.

25. FÁVERO, M. Estudo epidemiológico dos acidentes de trânsito em Ribeirão Preto. Ribeirão Preto, 1971. [Tese de Doutoramento - Faculdade de Medicina de Ribeirão Preto da USP].

26. FERREIRA, R.R. \& MENDES, R. Alguns aspectos epidemiológicos dos acidentes de trabalho fatais ocorridos em Campinas, SP (Brasil), 1972-1978. Rev. Saúde públ., S. Paulo, 15:251-62, 1981.

27. FINOCCHIARO, J. O traumatismo craniano na infortunistica: causas, sequelas e prevenção. In: Congresso Nacional de Prevenção de Acidentes de Trabalho, 16., Porto Alegre, 1977. Anais. São Paulo, Fundacentro/Ministério do Trabalho, 1977. p.325-7.

28. FINOCCHIARO, J. Consideraçðes sobre a gravidade do traumatismo craniano na infortunística. Rev. bras. Saúde ocup., 6(22):6-12, 1978. 
29. FLORENCE, J.C. Sulfocarbonismo. Rev. paul. Med., 56:445-56, 1960 .

30. GOLDSMITH, J.R. \& ARONOW, W.S. Carbon monoxide and coronary heart disease: a review. Environ. Res., 10:236-48, 1975.

31. GOTLIEB, S.L.D. Mortalidade diferencial por causas - São Paulo, 1970: tábuas de vida de múltiplo decremento. São Paulo, 1977. [Tese de Doutoramento - Faculdade de Saúde Pública da USP].

32. GUATELLI, M.A. et al. Intoxicaçס̄es profissionais por compostos arsenicais. In: Mendes, R., ed. Medicina do trabalho. Doenças profissionais. São Paulo, Sarvier, 1980. p.489-510.

33. GUIMARÃES, C. et al. Mortalidade de adultos de 15 a 74 anos de idade em São Paulo, Botucatu e São Manoel (Brasil), 1974/75. Rev. Saúde públ., S. Paulo, 13(Supl. 2), dez. 1979.

34. HARLAN, W.R. et al. Impact of the environment on cardiovascular disease: report of the American Heart Association Task Force on Environment and the Cardiovascular System. Circulation, 63(1):243A-6A, 1981.

35. HERNBERG, $S$. et al. Coronary heart disease among workers exposed to carbon disulphide. Brit. J. industr. Med., 27:313-25, 1970.

36. HERNBERG, S. et al. Angina pectoris, ECG findings and blood pressure of foundry workers in relation to carbon monoxide exposure. Scand. J. Wk Environ. Hlth, 2(Suppl. 1):54-63, 1976.

37. HIGGINSON, J. \& MUIR, C.S. Détermination de l'importance des facteurs environnementaux dans le cancer humain: rôle de l'épidémiologie. Bull. Cancer, Paris, 64:365.84, 1977.

38. HIGGINSON, J. \& MUIR, C.S. Environmental carcinogenesis: misconceptions and limitations to cancer control. J. Nat. Cancer Inst., 63:1291-8, 1979.

39. HOGSTEDT, C. \& ANDERSSON, K. A cohort study on mortality among dynamite workers. J. occup. Med., 21:553-6, 1979.

40. HOGSTEDT, C. \& AXELSON, O. Nitroglycerine-nitroglycol exposure and the mortality in cardio-cerebrovascular diseases among dynamite workers. J. occup. Med., 19:675-78, 1977.

41. INTERNATIONAL AGENCY FOR RESEARCH ON CANCER. IARC monographs on the evaluation of the carcinogenic risk of chemicals to humans. Lyon, 1982. (IARC Monographs, suppl. 4).

42. KARVONEN, M.J. Physical activity and cardiovascular morbidity. Scand. J. Wk Environ. Hlth, 10:389-95, 1984.

43. KOIZUMI, M.S. Aspectos epidemiológicos dos acidentes de motocicleta no Município de São Paulo, 1982. São Paulo, 1984. [Tese de Doutoramento Faculdade de Saúde Pública da USP].

44. KOSKELLA, R.S. et al. A mortality study of foundry workers. Scand. J. Wk Environ. Hlth, 2(Suppl. 1):73-89, 1976.

45. KURPPA, K. et al. Chemical exposures at work and cardiovascular morbidity. Scand. J. Wk Environ. Hlth, 10:381-8, 1984

46. LANGE, R.L. et al. Nonatheromatous ischemic heart disease following withdrawal from chronic industrial nitroglycerin exposure. Circulation, 46:666-78, 1972.

47. LAURENTI, R. O problema das doenças crônicas e degenerativas e dos acidentes nas áreas urbanizadas da América Latina. Rev. Saúde públ., S. Paulo., 9:239-48, 1975.

48. LAURENTI, R. Situação sanitária do Brasil. In:
Gonçalves, E.L., coord. Administraçdo de saúde no Brasili: Sæo Paulo, Pioneira, 1982. p.74-98.

49. LAURENTI, R. \& FONSECA, L.A.M. A evoluçăo da mortalidade por doenças isquêmicas do coração no município de São Paulo de 1940 a 1973. Arq. bras. Cardiol., 30:351-5, 1977.

50. LAURENTI, R. et al. Alguns aspectos epidemiológicos da mortalidade por acidentes de trânsito de veículos a motor na cidade de São Paulo, Brasil. Rev. Saúde públ., S. Paulo, 6:329-41, 1972.

51. LESSA, I. Doenças crônico-degenerativas. In: Rouquayrol, M.Z., ed. Epidemiologia \& saúde. Rio de Janeiro, Medsi, , 1986. p.331-42.

52. LOPES, R.M. Acidentes do trabalho na zona canavieira de Lençois Paulista. Rev. bras. Saúde ocup., 10(37):42-5, 1982.

53. LOPES, R.M. Acidentes do trabalho na agricultura, Botucatu, SP. Rev. bras. Saúde ocup., 10(39):12-7, 1982.

54. LOPES, R.M. Acidentes do trabalho na mão-de-obra volante empregada na agricultura (boias-frias), Botucatu, SP. São Paulo, 1983. [Dissertação de Mestrado - Faculdade de Medicina da USP].

55. LORENA, C. Prevenção de acidentes do trabalho no meio rural. In: Congresso Nacional de Prevenção de Acidentes do Trabalho, 16., Porto Alegre, 1977. Anais. São Paulo, Fundacentro/Ministério do Trabalho, 1977. p.50-7.

56. LUND, R.P. et al. Withdrawal symptoms in workers exposed to nitroglycerine. Brit. J. industr. Med., 25:136-8, 1968.

57. MATTOS FILHO, A. Acidente do trânsito encarado como acidente do trabalho: da segurança e prevenção do acidente de trânsito do ponto de vista médico. In: Congresso Nacional de Prevenção de Acidentes do Trabalho, 11:, Curitiba, 1972. Anais. Rio de Janeiro, Departamento Nacional de Segurança e Higiene do Trabalho, 1972. p.402-6.

58. McMICHAEL, A.J. et al. Mortality among rubber workers: relationship to specific jobs. J. occup. Med., 18:178-85, 1976.

59. MEDINA, M.C.G. A aposentadoria por invalidez no Brasil. São Paulo, 1986. [Dissertação de Mestrado - Faculdade de Medicina da USP].

60. MELLO JORGE, M.H.P. Mortalidade por causas violentas no Município de São Paulo. São Paulo, 1979. [Tese de Doutoramento - Faculdade de Saúde Pública da USP].

61. MELLO JORGE, M.H.P. Mortalidade por causas violentas no Município de São Paulo, Brasil. II Mortes acidentais. Rev. Saúde públ., S. Paulo., 14:475-508, 1980.

62. MELLO JORGE, M.H.P. Mortalidade por causas violentas no Municipio de São Paulo,-Brasil. IV A situação em 1980. Rev. Saúde públ., S. Paulo., 16:19-41, 1982.

63. MILLER, A.B. The etiology of bladder cancer from the epidemiological viewpoint. Cancer Res., 37:2939-42, 1977.

64. MONSON, R.R. \& FINE, L.J. Cancer mortality and morbidity among rubber workers. J. Nat. Cancer Inst., 61:1047-53, 1978.

65. MONTORO, A.F. \& NOGUEIRA, D.P., coord. Meio ambiente e câncer. São Paulo, T.A. Queiroz, 1983.

66. MORTON, W.E. Occupational habituation to aliphatic nitrates and the withdrawal hazards of coronary disease and hypertension. J. occup. Med., 19:197$200,1977$. 
67. NOGUEIRA, N. Educaçẵo de trânsito, prioridade nacional. Saúde ocup. Seg., 13:265-75, 1978.

68. NURMINEM, M. \& HERNBERG, S. Effects of intervention on cardiovascular mortality among workers exposed to carbon disulfide: a 15-year follow-up. [Abstract]. Scand. J. Wk Environ. Hlth, 10:131, 1984.

69. NURMINEM, M. et al. Quantitated effects of carbon disulfide exposure, elevated blood pressure and aging on coronary mortality. Amer. J. Epidem., 115:107-18, 1982.

70. OLIVAN FILHO, A. et al. Estudo epidemiológico dos acidentes do trabalho fatais na Grande São Paulo; no período de 1979 a 1982. Rev. bras. Saúde ocup., 12(46):7-13, 1984.

71. ORGANIZAÇÃO MUNDIAL DA SAÚDE. Definições e recomendações. In: MANUAL da classificação estatística internacional de doenças, lesoes e causas de óbito; revisão 1975. São Paulo, Centro da OMS para Classificação de Doenças em Português, 1978. p.803-9.

72. ORGANIZACIÓN PANAMERICANA DE LA SALUD. Salud ocupacional en la America Latina y el Caribe: consideraciones sobre algunos problemas, aiternativas, tendencias y desafios para su promoción. Washington, D.C., 1981. [Mimeografado].

73. PARKES, H.G. et al. Cancer mortality in the British rubber industry. Brit. J. industr. Med., 39:209-20, 1982.

74. PASTORELO, E.F. Mortalidade por câncer no Distrito de São Paulo, 1962/1963 e 1974/1975. São Paulo, 1980. [Dissertação de Mestrado - Faculdade de Saúde Pública da USP].

75. PAULINO, O. Introdução ao problema do câncer ocupacional. Rev. bras. Saúde ocup., 8(31):26-31, 1980.

76. PINTO, J.B. Os atropelamentos como acidentes do trabalho. In: Congresso Nacional de Prevenção de Acidentes do Trabalho, 13:, São Paulo, 1974. Anais. São Paulo, Fundacentro, 1974. p. 443-7

77. PUFFER, R.R. \& GRIFFITH, G.W. Patterns of urban mortality. Washington, D.C., Pan American Health Organization, 1967. (PAHO - Scientific Publication, 151).

78. PUGLIESE, C. et al. Aspectos epidemiológicos dos acidentes fatais a veículo a motor na cidade de Salvador (Bahia), Brasil. Rev. Saúde públ., S. Paulo, 9:271-83, 1975 .

79. RAMOS, J.V. et al. A segurança no trânsito, novo conceito de segurança do trabalho. In: Congresso Nacional de Prevenção de Acidentes do Trabalho, 13․, São Paulo, 1974. Anais. São Paulo, Fundacentro, 1974. p. 787-93.

80. RANTANEN, J. Effect of accidents on public health and national economy. J. occup. Accid., 4:195-203, 1982.

81. RANTANEN, J. Occupational health and safety in Finland. Scand. J.Wk Environ. Hlth, 9(Sp. issue 2):140-7, 1983.

82. REDMOND, C.K. et al. Cancer experience among coke by-product workers. Ann. N.Y. Acad. Sci., 271:102-15, 1976.

83. REDMOND, C.K. et al. Long-term mortality study of steelworkers. VI - Mortality from malignant neoplasms among coke oven workers. J. occup. Med:; 14:621-9, 1972.

84. RIBEIRO, B.A. et al. Exposição ao sulfeto de carbono e sulfeto de hidrogênio na fabricação do raiom pelo processo da viscose, no Estado de São
Paulo. Arq. Fac. Hig. S. Paulo, 13(1):219-41, 1959.

85. RODRIGUES, A.C. \& MARANHÃO, O.R. Exposição do sulfureto de carbono - consideraçðes acerca de 50 casos. Saúde ocup. Seg., 10(1):33-40; 1975.

86. RODRIGUES, V.L.G.S. Acidentes rodoviários com trabalhadores volantes na agricultura. Rev. bras. Saúde ocup., 11(42):46-52, 1983.

87. ROSENMAN, K.D. Cardiovascular disease and environmental exposure. Brit. J. industr. Med., 36: 85-97, 1979.

88. ROSENMAN, K.D. Cardiovascular disease and work place exposures. Arch. environ. Hlth. 39:218-24, 1984.

89. SAFFIOTTI, U. \& WAGONER, J.K., eds. Occupational carcinogenesis. Ann. N.Y. Acad. Sci., 271:1$516,1976$.

90. SCHILLING, R.S.F. More effective prevention in occupational health practice? J. Soc. occup. Med., 34:71-9, 1984.

91. SCHOTTENFELD, D. Chronic disease in the workplace and environment: cancer. Arch. environ. Hith, 39:150-7, 1984.

92. SEGRE, M. \& PÁSCOA, M.P. Acidentes do trabatho incapacitantes e mortais em regiano pouco industrializada: Botucatu-SP. In: Congresso Nacional de Prevenção de Acidentes do Trabalho, 13:, São Paulo, 1974. Anais. São Paulo, Fundacentro, 1974. p. $389-408$.

93. SILVA, M.G.C. Anos potenciais de vida perdidos segundo causas, em Fortaleza (Brasil), 1978-80. Rev. Saúde públ., S. Paulo., 18:108-21, 1984.

94. SIQUEIRA, M.L. et al. Diagnóstico dos problemas ecotoxicologicos causados pelo uso de defensivos agrícolas no Estado do Paraná. Rev. bras. Saúde ocup., 11(44):7-17, 1983.

95. TAMBELLINI, A.T. Contribuição d análise epidemiológica dos acidentes de trânsito. Campinas, 1975. [Tese de Doutoramento - Faculdade de Ciências Médicas da UNICAMP].

96. TEIXEIRA, J.W. Acidentes do trabalho com óbitos: estudo da mortalidade ocorrida em Santa Catarina no ano de 1981. Rev. bras. Saúde ocup., 10(40):31$5,1982$.

97. TILLER, J.R. et al. Occupational toxic factor in mortality from coronary heart disease. Brit. med. J., 4:407-11, 1968.

98. TIMIO, M. Clases sociales y enfermedad: introducción a una epidemiología diferencial. México, Nueva Imagen, 1980.

99. TOLONEN, M. et al. A follow-study of coronary heart disease in viscose rayon workers exposed to carbon disulphide. Brit. J. industr. Med., 32:1-10, 1975.

100. TOLONEN, M. et al. Ten-year coronary mortality of workers exposed to carbon disulfide. Scand. $J$. Wk Environ. Hlth, 5:109-14, 1979.

101. TOMATIS, L. Occupational cancer (legislation). In: Encyclopaedia of Occupational Health and Safety. $3^{\text {rd }}$ ed. Geneva, International Labour Office, 1983. v. 1, p. 376-7.

102. TRAPE, A.Z. et al. Projeto de vigilância epidemiológica em ecotoxicologia de pesticidas. Rev. bras. Saúde ocup., 12(47):12-20, 1984.

103. USA. Public Health Service. National Institute of Environmental Health Sciences. Human health and the environment: some research needs. Washington, D.C., 1977. (DHEW Publication n: NIH 77. 1277). 
104. VEYS, C.A. Bladder tumours and occupation: a coroner's notification scheme. Brit. J. industr. Med., 31:65-71, 1974.

105. VIEIRA, H.R.A. et al. Contribuição ao conhecimento dos acidentes do trabalho rural no Estado do $\mathrm{Pa}$ raná. Rev. bras. Saúde ocup., 11(44):50-66, 1983.

106. VIGLIANI, E.C. Leukemia associated with benzene exposure. Ann. N.Y. Acad. Sci., 271:143-51, 1976.

107. WAGONER, J.K. Occupational carcinogenesis: the two hundred years since Percivall Pott. Ann. N.Y. Acad. Sci., 271:1-4, 1976.

108. WEIR, F.W. \& FABIANO, U.L. Reevaluation of the role of carbon monoxide in production or aggravation of cardiovascular disease processes. J. occup. Med., 24:519-25, 1982.

109. WILLS, J.H. Nasal carcinoma in woodworkers: a review. J. occup. Med. 24:526-30, 1982.
110. WORLD HEALTH ORGANIZATION. Carbon disulfide. Geneva, 1979. (Environmental Health Criteria, 10).

111. WORLD HEALTH ORGANIZATION. Expert Committee on Prevention of Cancer, Geneva, 1963. Report. Geneva, 1964. (Technical Report Series, 276).

112. WINDER, E.L. \& GORI, G.B. Contribution of the environment to cancer incidence: an epidemiologic exercise. J. Natl. Cancer Inst., 58:825-32, 1977.

Recebido para publicação em 18/1/1988 Aprovado para publicação em 15/4/1988 